\title{
Front Matter: Volume 7519
}

, "Front Matter: Volume 7519," Proc. SPIE 7519, Eighth International Conference on Photonics and Imaging in Biology and Medicine (PIBM 2009), 751901 (2 November 2009); doi: 10.1117/12.853028 


\title{
Eighth International Conference on \\ Photonics and Imaging \\ in Biology and Medicine (PIBM 2009)
}

\author{
Qingming Luo \\ Lihong V. Wang \\ Valery V. Tuchin \\ Pengcheng Li \\ Ling Fu \\ Editors
}

\section{8-10 August 2009 \\ Wuhan, China}

Organized by

Wuhan National Laboratory for Optoelectronics (China)

Sponsored by

Chinese Optical Society • Huazhong University of Science and Technology (China) • China Hubei Provincial Science Technology Department - Administration Committee of Wuhan East Lake High-Tech Development Zone (China) • The State Optoelectronic Information Industry Base of China

\section{Supported by}

Ministry of Education of China - Optical Society of America - Laser Institute of America - Frontiers of Optoelectronics in China • Editorial Office of Optics \& Optoelectronics Technology • Opticsjournal.net OFweek.com • The China Science-Meeting Online • Laser Manufacture News

Published by

SPIE

Volume 7519 
The papers included in this volume were part of the technical conference cited on the cover and title page. Papers were selected and subject to review by the editors and conference program committee. Some conference presentations may not be available for publication. The papers published in these proceedings reflect the work and thoughts of the authors and are published herein as submitted. The publisher is not responsible for the validity of the information or for any outcomes resulting from reliance thereon.

Please use the following format to cite material from this book:

Author(s), "Title of Paper," in Eighth International Conference on Photonics and Imaging in Biology and Medicine (PIBM 2009), edited by Qingming Luo, Lihong V. Wang, Valery V. Tuchin, Pengcheng Li, Ling Fu, Proceedings of SPIE Vol. 7519 (SPIE, Bellingham, WA, 2009) Article CID Number.

ISSN $1605-7422$

ISBN 9780819479082

Published by

SPIE

P.O. Box 10, Bellingham, Washington $98227-0010$ USA

Telephone +1 3606763290 (Pacific Time) · Fax +1 3606471445

SPIE.org

Copyright ( 2009, Society of Photo-Optical Instrumentation Engineers.

Copying of material in this book for internal or personal use, or for the internal or personal use of specific clients, beyond the fair use provisions granted by the U.S. Copyright Law is authorized by SPIE subject to payment of copying fees. The Transactional Reporting Service base fee for this volume is $\$ 18.00$ per article (or portion thereof), which should be paid directly to the Copyright Clearance Center (CCC), 222 Rosewood Drive, Danvers, MA 01923. Payment may also be made electronically through CCC Online at copyright.com. Other copying for republication, resale, advertising or promotion, or any form of systematic or multiple reproduction of any material in this book is prohibited except with permission in writing from the publisher. The CCC fee code is 1605$7422 / 09 / \$ 18.00$.

Printed in the United States of America.

Publication of record for individual papers is online in the SPIE Digital Library.

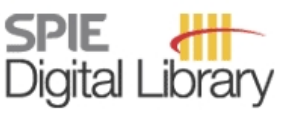

SPIEDigitalLibrary.org

Paper Numbering: Proceedings of SPIE follow an e-First publication model, with papers published first online and then in print and on CD-ROM. Papers are published as they are submitted and meet publication criteria. A unique, consistent, permanent citation identifier (CID) number is assigned to each article at the time of the first publication. Utilization of CIDs allows articles to be fully citable as soon they are published online, and connects the same identifier to all online, print, and electronic versions of the publication. SPIE uses a six-digit CID article numbering system in which:

- The first four digits correspond to the SPIE volume number.

- The last two digits indicate publication order within the volume using a Base 36 numbering system employing both numerals and letters. These two-number sets start with 00, 01, 02, 03, 04, $05,06,07,08,09,0 A, 0 B \ldots 0 Z$, followed by 10-1Z, 20-2Z, etc.

The CID number appears on each page of the manuscript. The complete citation is used on the first page, and an abbreviated version on subsequent pages. Numbers in the index correspond to the last two digits of the six-digit CID number. 


\section{Contents}

EIGHTH INTERNATIONAL CONFERENCE ON PHOTONICS AND IMAGING IN BIOLOGY AND MEDICINE (PIBM 2009)

751902 A comparison study of microarrays by fluorescence imaging and surface plasmon resonance imaging [7519-58]

Z. Liu, C. Zhang, B. Yang, X. Chong, L. Liu, S. Ma, Y. He, G. Zhang, J. Guo, Tsinghua Univ. (China)

751903 A meta-analysis of aneurysm formation in laser assisted vascular anastomosis (LAVA) [7519-33]

C. Chen, Yangtze Univ. (China); F. Peng, Tongji Hospital, Huazhong Univ. of Science and Technology (China); D. Xu, Q. Cheng, Yangtze Univ. (China)

751904 A novel cancer-targeting transporter with integrin $\alpha_{v} \beta_{3}$ monoclonal antibody functionalized single-walled carbon nanotubes [7519-69]

Z. OU, B. WU, D. Xing, South China Normal Univ. (China)

751905 A novel spectral calibration method in spectral domain optical coherence tomography [7519-62]

L. Duan, Y. He, Tsinghua Univ. (China)

751906 A portable Vis-NIR spectrometer to determine soluble solids content in Gannan navel orange by LS-SVM and EWs selection [7519-52]

Y. Liu, Y. Pan, A. Ouyang, X. Sun, H. Zhang, East China Jiaotong Univ. (China)

751907 Application of infrared thermal imaging in the study of preventing cardiovascular and cerebrovascular diseases with Chinese medicine health food [7519-88]

Z. Li, South China Normal Univ. (China); X. Zhang, Biological Pharmaceutical Institute of Ezhou (China)

751908 Application thinking on Bian-stone of the acousto-optic effect in the treatment of primary dysmenorrhea [7519-105]

S. Ge, G.-Z. Chen, S.-H. Liu, South China Normal Univ. (China)

751909 Assessment of the effect of narrowband UVB and broadband UVB on mice skin using optical coherence tomography [7519-84]

Z. Liu, Z. Guo, J. Zhai, H. Xiong, C. Zeng, Y. Jin, South China Normal Univ. (China)

7519 OA Biomedical images texture detail denoising based on PDE [7519-44]

G. Chen, Fujian Normal Univ. (China) and Huazhong Univ. of Science and Technology (China); J. Pan, C. Li, Fujian Provincial Tumor Hospital (China); R. Chen, Fujian Normal Univ. (China) and Xiamen Univ. (China); J. Lin, Fujian Normal Univ. (China); K. Yan, Huazhong Univ. of Science and Technology (China); Z. Huang, Fujian Normal Univ. (China) 
7519 OB Collagen remodeling in photo-thermal damaged skin with optical coherence tomography and multiphoton microscopy [7519-31]

S. Wu, H. Li, X. Zhang, L. Yu, Fujian Normal Univ. (China)

7519 OC Comparison between the changes in muscle oxygenation and blood lactate concentration in finswimmers during incremental exercise [7519-121]

B. Wang, Q. Tian, Z. Zhang, H. Gong, Huazhong Univ. of Science and Technology (China)

7519 OD Design of a real-time pyrosequencer by bioluminometric assay coupled with photodiode array [7519-86]

H. Chen, Huadong Research Institute for Medicine and Biotechnics (China) and Institute of Semiconductors (China); C. Liang, C. Li, C. Li, J. Ge, Y. Zhang, G. Zhou, Huadong Research Institute for Medicine and Biotechnics (China)

7519 OE Detection of biochemical reactions by a surface plasmon resonance sensor based on polarization interferometry and angle modulation [7519-71]

Z. Hu, X. Chong, S. Ma, Y. Li, Y. He, J. Guo, Tsinghua Univ. (China)

7519 OF Differentiating normal and cancerous stroma by nonlinear spectral imaging [7519-35]

S. Zhuo, J. Chen, S. Xie, L. Zheng, X. Zhu, X. Jiang, Fujian Normal Univ. (China)

7519 OG Dual-modality imaging system combined fast photoacoustic imaging and ultrasound imaging [7519-123]

L. Xiang, Y. Yuan, South China Normal Univ. (China)

$7519 \mathrm{OH} \quad$ Dynamic and label-free high-throughput detection of biomolecular interactions based on phase-shift interferometry [7519-114]

Q. Li, G. Huang, Tsinghua Univ. School of Medicine (China) and National Engineering Research Ctr. for Beijing Biochip Technology (China); W. Gan, National Engineering Research Ctr. for Beijing Biochip Technology (China); S. Chen, Tsinghua Univ. School of Medicine (China) and National Engineering Research Ctr. for Beijing Biochip Technology (China)

7519 Ol Experimental research of two-wavelength laser ablation biological tissue [7519-1111] Y. Yao, C. Huang, Hubei Univ. of Technology (China); Y. He, Huazhong Univ. of Science and Technology (China); X. Chen, Hubei Univ. of Technology (China)

$75190 \mathrm{~J} \quad$ Experimental study of the optimal metal film for surface plasmon resonance [7519-66] C. Du, L. Liu, S. Ma, Z. Liu, Tsinghua Univ. (China); J. Zhu, Tongji Univ. (China); Y. He, Tsinghua Univ. (China); Z. Wang, Tongji Univ. (China); J. Guo, Tsinghua Univ. (China)

7519 OK Functional single-walled carbon nanotubes/chitosan conjugate for tumor cells targeting [7519-67]

B. Wu, Z. Ou, D. Xing, South China Normal Univ. (China)

$7519 \mathrm{OL} \quad$ High-contrast photoacoustic imaging based on filtered back-projection algorithm with velocity potential integration [7519-23]

Y. Yuan, D. Xing, L. Xiang, South China Normal Univ. (China) 
7519 OM Hydrogen peroxide generated by NADPH oxidase is involved in high blue-light-induced chloroplast avoidance movements in Arabidopsis [7519-29]

F. Wen, D. Xing, L. Zhang, South China Normal Univ. (China)

7519 ON Imaging calibration of thermoacoustic tomography distortion caused by microwave diffraction [7519-46]

L. Nie, D. Xing, South China Normal Univ. (China)

$751900 \quad$ Immobilization of human papillomavirus DNA probe for surface plasmon resonance imaging [7519-107]

X. Chong, Tsinghua Univ. (China); Y. Ji, South China Normal Univ. (China); S. Ma, L. Liu, Z. Liu, Y. Li, Y. He, J. Guo, Tsinghua Univ. (China)

7519 OP In vivo tumor imaging in mice with near-infrared: low density lipoprotein conjugates [7519-131]

X. Chen, D. Deng, F. Liu, H. Li, China Pharmaceutical Univ. (China); Z. Qian, Nanjing Univ. of Aeronautics and Astronautics (China); Y. Gu, China Pharmaceutical Univ. (China)

$75190 Q \quad$ In vivo XRF measurement of lead in bone: theory and important progress [7519-01] W. Yi, X. Luo, Huazhong Agricultural Univ. (China)

7519 OR Label-free and dynamic detection of biomolecular interactions based on surface plasmon resonance imaging for high-throughput microarray applications [7519-122]

S. Chen, Q. Li, T. Deng, G. Huang, Tsinghua Univ. School of Medicine (China) and National Engineering Research Ctr. for Beijing Biochip Technology (China)

7519 OS Laser assisted vascular anastomosis (LAVA): a promising nonsuture technique for surgery [7519-34]

C. Chen, Yangtze Univ. (China); F. Peng, Tongji Hospital, Huazhong University of Science and Technology (China); D. Xu, Q. Cheng, Yangtze Univ. (China)

7519 OT Low-power laser irradiation inhibits $A \beta_{25-35}$-induced cell apoptosis through Akt activation [7519-90]

Z. Zhang, Y. Tang, South China Normal Univ. (China)

7519 OU Measurement of degree of orientation of high polymer using rotating linear polarization imaging [7519-76]

D. Li, R. Liao, N. Zeng, Y. He, H. Ma, Tsinghua Univ. (China)

7519 OV Measurement of glucose concentration in interstitial fluid by surface plasmon resonance with D-galactose/D-glucose binding protein [7519-95]

D. C. Li, J. X. Zhang, P. Wu, F. X. Huang, B. Song, K. X. Xu, Tianjin Univ. (China)

7519 OW Microscopic mechanism analyses on influence of metabolism of erythrocyte membrane-lipid etc. by LLLIB [7519-128]

L. Xu, Yunnan Normal Univ. (China); C. Zhang, Honghe College (China); Y. Wen, Yunnan Normal Univ. (China); S. Liu, Kunming General Hospital of Chengdu Military Command (China); L. Zhou, Kunming Univ. of Science and Technology (China) and Yunnan Normal Univ. (China) 
7519 OX Monitoring of tumor treatment using the combination of near-infrared laser light and carbon nanotubes [7519-42]

W. Chen, South China Normal Univ. (China) and Univ. of Central Oklahoma (United States);

F. Zhou, Z. Ou, B. Wu, S. Song, South China Normal Univ. (China)

7519 OY Monitoring tumor metastasis by in vivo imaging and flow cytometer [7519-103]

Z. Gu, Xinhua Hospital, Shanghai Jiaotong Univ. (China); J. Guo, G. Liu, Y. Li, Y. Chen, Fudan Univ. (China); T. Chen, Huashan Hospital, Fudan Univ. (China); C. Wang, Univ. of Shanghai for Science and Technology (China); X. Wei, Fudan Univ. (China)

$75190 Z$ Morphological analysis of dentin tissue after Er, Cr: YSGG laser irradiation [7519-100] L. Yu, Fujian Normal Univ. (China); Q. Lin, Affiliated Stomatological Hospital, Fujian Medical Univ. (China); X. Zhang, Z. Zhan, Fujian Normal Univ. (China); S. Lin, Affiliated Stomatological Hospital, Fujian Medical Univ. (China); S. Xie, Fujian Normal Univ. (China)

751910 Multiwavelength adaptive optical fundus camera and continuous retinal imaging [7519-127]

$\mathrm{H}$. Yang, The Key Lab. on Adaptive Optics (China), Institute of Optics and Electronics (China), and Graduate School of the Chinese Academy of Sciences (China); M. Li, Y. Dai, Y. Zhang, The Key Lab. on Adaptive Optics (China) and Institute of Optics and Electronics (China)

$751911 \quad$ Noninvasive detection of glucose concentration by differential absorption OCI with two wavelengths [7519-65]

Y. Li, Y. He, X. Dai, P. Li, L. Duan, Y. Zhou, N. Zeng, Tsinghua Univ. (China)

751912 Novel nano drug delivery systems for hepatic tumor [7519-112]

Y. Cao, J. Liu, H. Ma, J. Bai, C. Qi, Central China Normal Univ. (China)

751913 Particle tracking carboxyl and transferrin conjugated quantum dots diffusion at living cell surface [7519-97]

T. Tian, Z. Zhu, Z. Xiao, Southeast Univ. (China)

751914 Pathological process investigation of Jadassohn-Pellizzari anetoderma based on multiphoton microscopy [7519-37]

J. Chen, Fujian Normal Univ. (China); J. Zhao, Y. Yang, Affiliated Union Hospital, Fujian Medical Univ. (China); S. Zhuo, X. Jiang, Fujian Normal Univ. (China); W. Tian, X. Ye, L. Lin, Affiliated Union Hospital, Fujian Medical Univ. (China)

751915 Photoacoustic and thermoacoustic imaging for biomedical applications [7519-38]

S. Yang, D. Xing, L. Nie, H. Guo, S. Ma, South China Normal Univ. (China)

751916 Preliminary study on the time-related changes of the infrared thermal images of the human body [7519-91]

Z. Li, South China Normal Univ. (China); X. Zhang, Biological Pharmaceutical Institute of Ezhou (China); G. Lin, Z. Chen, Guangzhou Central Meteorological Observatory (China)

751917 Probing of marker proteins in cancer tissue using quantum dots with Hadamard transform fluorescence imaging microscopy [7519-32]

H. Xu, Wuhan Univ. (China); C. Chen, Y. Li, Zhongnan Hospital, Wuhan Univ. (China) and Hubei Key Lab. of Tumor Biological Behaviors (China); H.-W. Tang, Wuhan Univ. (China) 
751918 Profile analysis of ventricle specimen based on a new phase measuring method [7519-47]

Y. Cao, X. Su, W. Chen, L. Xiang, Q. Zhang, Y. Liu, Sichuan Univ. (China)

751919 Protein kinase C $\delta$ promotes cell apoptosis induced by high fluence low-power laser irradiation [7519-28]

H. Zhang, D. Xing, S. Wu, X. Sun, South China Normal Univ. (China)

7519 1A PUMA promotes Bax translocation in FOXO3a-dependent pathway during STS-induced apoptosis [7519-14]

Y. Zhang, Q. Chen, South China Normal Univ. (China)

7519 1B Quantified characterization of dermal collagen structure in human cutaneous scars from second harmonic generation imaging [7519-64]

X. Zhu, Fujian Normal Univ. (China); Y. Chen, First Affiliated Hospital, Fujian Medical Univ.

(China); S. Zhuo, B. Yu, L. Zheng, K. Lu, J. Chen, Fujian Normal Univ. (China)

7519 1C Quantitative analysis on PUVA-induced skin photodamages using optical coherence tomography [7519-102]

J. Zhai, Z. Guo, Z. Liu, H. Xiong, C. Zeng, Y. Jin, South China Normal Univ. (China)

7519 1D Raman and surface enhanced Raman spectroscopy of amino acids and peptide [7519-74] X. Yuan, H. Gu, J. Wu, J. Kang, X. Dong, South China Normal Univ. (China)

$75191 \mathrm{E} \quad$ Raman spectra and discrimination of NPC cell line CNE1 and normal nasopharyngeal cell line NP69 [7519-108]

Y. Chen, Y. Li, Fujian Normal Univ. (China); Y. Su, Fujian Provincial Tumor Hospital (China);

J. Lin, Fujian Normal Univ. (China); J. Pan, Fujian Provincial Tumor Hospital (China); R. Chen, Fujian Normal Univ. (China) and Xiamen Univ. (China); C. Zou, S. Lin, C. Li, Fujian Provincial Tumor Hospital (China)

7519 iF Raman spectral study of anti-angiogenic drugs on the role of chick vascular [7519-109] R. Huang, Fujian Normal Univ. (China); R. Chen, Fujian Normal Univ. (China) and Xiamen Univ. (China); Q. Chen, Fujian Provincial Tumor Hospital (China); J. Lin, Fujian Normal Univ. (China); J. Pan, S. Lin, C. Li, Fujian Provincial Tumor Hospital (China); Y. Li, S. Feng, Fujian Normal Univ. (China)

7519 1G Raman spectroscopic analysis of cytotoxic effect of cisplatin-treated leukemic cells [7519-110]

J. Lin, Y. Li, S. Feng, Fujian Normal Univ. (China); R. Chen, Fujian Normal Univ. (China) and Xiamen Univ. (China); G. Chen, Fujian Normal Univ. (China); Q. Chen, J. Pan, S. Lin, Fujian Provincial Tumor Hospital (China); Y. Yu, Fujian Normal Univ. (China)

$75191 \mathrm{H} \quad$ Recognition of gastric cancer by Raman spectroscopy [7519-117] M. Xu, J. Ma, Y. Qu, Ocean Univ. of China (China); W. Mao, Qingdao Univ. Medical College Hospital (China); R. Zheng, Ocean Univ. of China (China)

$751911 \quad$ Retina imaging in vivo with the adaptive optics confocal scanning laser ophthalmoscope [7519-125]

J. Lu, H. Li, L. Wei, G. Shi, Institute of Optics and Electronics (China), The Key Lab. on Adaptive Optics (China), and Graduate School of Chinese Academy of Sciences (China); Y. Zhang, Institute of Optics and Electronics (China) and The Key Lab. on Adaptive Optics (China) 
$75191 \mathrm{~J}$ Sensitive detection and quantitation of EZH2 expression in cancer cell by an electrochemiluminescent method [7519-55]

Q. Li, X. Zhou, South China Normal Univ. (China)

$75191 \mathrm{~K}$ Single molecular image of cytosolic free $\mathrm{Ca}^{2+}$ of skeletal muscle cells in rats pre- and post-exercise-induced fatigue [7519-68]

Y. Liu, H. Zhang, Y. Zhao, Z. Liu, South China Normal Univ. (China)

$75191 \mathrm{~L}$ Study on conditions of DNA immobilization by surface plasmon resonance imaging [7519-60]

L. Liu, C. Zhang, Z. Liu, X. Chong, S. Ma, Y. He, G. Zhang, J. Guo, Tsinghua Univ. (China)

$75191 \mathrm{M}$ Study on surface-enhanced Raman scattering efficiency of Ag core-Au shell bimetallic nanoparticles [7519-73]

X. Dong, H. Gu, J. Kang, X. Yuan, South China Normal Univ. (China)

$75191 \mathrm{~N}$ The biocompatibility of the dermal injection of glycerol in vivo to achieve optical clearing [7519-78]

Z. Mao, Wuhan Institute of Physical Education (China) and Huazhong Univ. of Science and Technology (China); X. Wen, J. Wang, D. Zhu, Huazhong Univ. of Science and Technology (China)

751910 The character of biological tissue's SHG spectrum [7519-106]

L. Tian, Z. Guo, X. Deng, J. Zhai, Z. Zhuang, South China Normal Univ. (China)

7519 1P The effect of aqueous solution in Raman spectroscopy [7519-41]

J. Kang, X. Yuan, X. Dong, H. Gu, South China Normal Univ. (China)

$75191 Q \quad$ The simulation of diode side-pumped Tm:YAG laser [7519-116]

X. Chen, C. Huang, Y. Yao, X. Yan, T. Yang, Y. Kong, Y. Wang, Hubei Univ. of Technology (China)

7519 IR The surface enhanced Raman spectroscopy of DCM in silver colloid [7519-27] S. Feng, J. Chen, Fujian Normal Univ. (China); Q. Chen, J. Pan, Fuzhou Cancer Hospital (China); R. Chen, Fujian Normal Univ. (China) and Xiamen Univ. (China); S. Lin, C. Li, Fuzhou Cancer Hospital (China)

7519 is Thermoacoustic measurement of the temperature during microwave thermotherapy [7519-24]

C. Lou, D. Xing, L. Nie, South China Normal Univ. (China)

$75191 \mathrm{~T}$ Thinking on the application of nanotechnology in the mechanism research on the acupuncture treatment of female climacteric syndrome [7519-94]

Y. XU, South China Normal Univ. (China) and Guangzhou Univ. of Chinese Medicine (China);

J. Cai, Guangzhou Univ. of Chinese Medicine (China); G. Chen, South China Normal Univ.

(China); P. Chen, Guangzhou Univ. of Chinese Medicine (China)

$75191 \mathrm{U}$ Transmissive RSOD for balance-detection-based OCT [7519-40]

L. Xu, Z. Ding, K. Wang, T. Wu, Zhejiang Univ. (China) 
$75191 \mathrm{~V} \quad$ Using ultra-weak luminescence to evaluate $\mathrm{NaCl}$ stress resistance of maize varieties [7519-56]

G. Chi, DeZhou Univ. (China)

7519 1W Visualization of reproduction toxicity of QDs for in vitro oocytes maturation [7519-83]

G. Xu, X. Lin, Shenzhen Univ. (China); K.-T. Yong, I. Roy, The State Univ. of New York at Buffalo (United States); J. QU, X. Wang, Shenzhen Univ. (China)

$75191 \mathrm{X} \quad$ White light source spectral domain OCT based on partial spectrum analysis [7519-07] N. Yao, J. Wang, Y. Zheng, Tianjin Polytechnic Univ. (China)

Author Index 
Downloaded From: https://www.spiedigitallibrary.org/conference-proceedings-of-spie on 26 Apr 2023

Terms of Use: https://www.spiedigitallibrary.org/terms-of-use 


\section{Conference Committee}

Chairs

Qingming Luo, Wuhan National Laboratory for Optoelectronics (China) Lihong V. Wang, Washington University in St. Louis (United States)

Valery V. Tuchin, Saratov State University (Russian Federation)

Advisory Committee

Sydney Brenner, Salk Institute for Biological Studies (United States)

Howard Chen, K\&L Gates (United States)

Jing Cheng, Tsinghua University (China)

Paul Ching-Wu Chu, The Hong Kong University of Science and Technology (Hong Kong, China)

Aaron Ciechanover, Technion-Israel Institute of Technology (Israel)

A. Stephen Dahms, Alfred E. Mann Foundation for Biomedical Engineering (United States)

Da Hsuan Feng, National Cheng Kung University (Taiwan, China)

Steven R. Goodman, SUNY Upstate Medical University (United States)

Barry Halliwell, National University of Singapore (Singapore)

John Hart, The University of Texas at Dallas (United States)

George Radda, A*STAR-Agency for Science, Technology and

Research (Singapore)

Zihe Rao, Nankai University (China)

Brian M. Salzberg, University of Pennsylvania (United States)

Ruey-Jen Sung, Stanford University (United States)

A. Dean Sherry, The University of Texas at Dallas (United States)

Bruce Tromberg, University of California, Irvine (United States)

Fujia Yang, The University of Nottingham (United Kingdom)

Jianquan Yao, Tianjin University (China) and Wuhan National Laboratory for Optoelectronics (China)

Yixin Zeng, Sun Yat-sen University Cancer Center (China)

Baoyong Zheng, Huawei Technologies Corporation, Inc. (China)

\section{Program Committee}

Wei R. Chen, University of Central Oklahoma (United States)

Zhongping Chen, University of California, Irvine (United States)

Arthur Chiou, National Yang-Ming University (Taiwan, China)

Frank Y. S. Chuang, University of California, Davis (United States)

Zhihua Ding, Zhejiang University (China)

Congwu Du, Brookhaven National Laboratory (United States) 
Weiping Han, A*STAR-Agency for Science, Technology and Research (Singapore)

Chang-Deng Hu, Purdue University (United States)

Zheng Huang, University of Colorado Health Sciences Center (United States)

Zhiwei Huang, National University of Singapore (Singapore)

Steven L. Jacques, Oregon Health \& Science University (United States)

Fu-Jen Kao, National Yang-Ming University (Taiwan, China)

Hideaki Koizumi, Hitachi, Ltd. (Japan)

Xingde Li, Johns Hopkins University (United States)

Yong-qing Li, East Carolina University (United States)

Chengyi Liu, South China Normal University (China)

Hong Liu, University of Oklahoma (United States)

Zuhong Lu, Southeast University (China)

Dennis L. Matthews, University of California, Davis (United States)

Avraham Mayevsky, Bar-llan University (Israel)

Igor V. Meglinski, Cranfield University (United Kingdom)

Stephen P. Morgan, The University of Nottingham (United Kingdom)

Shoko Nioka, University of Pennsylvania (United States)

Yingtian Pan, State University of New York at Stony Brook (United States)

Alexander V. Priezzhev, M.V. Lomonosov Moscow State University (Russian Federation)

Jianan Y. Qu, The Hong Kong University of Science and Technology (Hong Kong, China)

Colin J. R. Sheppard, National University of Singapore (Singapore)

Mamoru Tamura, Hokkaido University (Japan)

Sergey Ulyanov, Saratov State University (Russian Federation)

Ruikang K. Wang, Oregon Health \& Science University (United States)

Xunbin Wei, Fudan University (China)

Da Xing, South China Normal University (China)

Kexin Xu, Tianjin University (China)

Xincheng Yao, University of Alabama at Birmingham (United States)

Haishan Zeng, BC Cancer Research Centre (Canada)

Gang Zheng, University of Toronto (Canada)

Dongping Zhong, The Ohio State University (United States)

Timothy Chongde Zhu, University of Pennsylvania (United States)

Local Organizing Committee Chairs

Pengcheng Li, Wuhan National Laboratory for Optoelectronics (China)

Ling Fu, Wuhan National Laboratory for Optoelectronics (China) 